\title{
Reflexión acerca del ejercicio audiovisual como medio de expresión del diseño gráfico experimental
}

\section{Alcalde Fierro, María José}

Resumen: Este artículo se adentra en una reflexión sobre los distintos aspectos que hacen al diseño experimental haciendo especial hincapié en lo relativo a la enseñanzaaprendizaje.

Palabras clave: Diseño experimental enseñanza - aprendizaje.

${ }^{*}$ ) Licenciada en Diseño Gráfico, Universidad Mayor. Jefe de Carrera Diseño Gráfico. Docente Diseño Editorial, Diseño de Marca y Web, Instituto Profesional Santo Tomás Valdivia, Chile.

En el ejercicio diario de la enseñanza del diseño gráfico utilizamos variados recursos para que nuestros

Cuadernos del Centro de Estudios de Diseño y Comunicación Nº 66

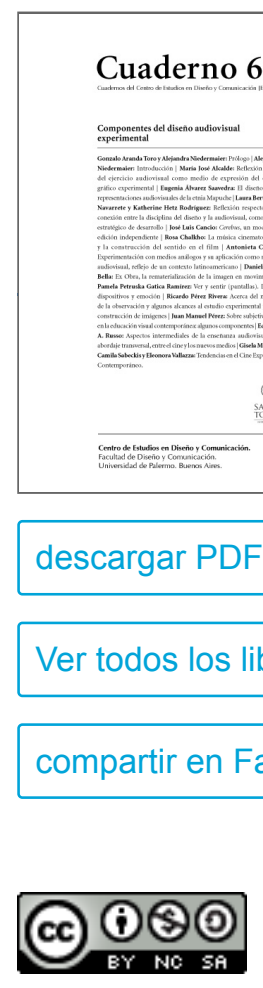

Esta obra está bajo una Licencia Creative Commons Atribución-NoComercialCompartirlgual 4.0 Internacional

estudiantes logren entender las

distintas dimensiones que

comprenden el Diseño Gráfico y su ejercicio.

Los primeros esfuerzos son para que puedan conocer las distintas áreas de acción donde se van a poder desempeñar como diseñadores; como lo es el Diseño Editorial, el Diseño Corporativo, la Publicidad, el Diseño Web, el Diseño Audiovisual o la creación de un packaging. Y luego comenzamos a adentrarnos en la materia y nuestros esfuerzos se vuelcan a lograr que los estudiantes puedan comprender y aplicar lo estudiado.

Creemos que una de las formas de desafiar, motivar y generar un aprendizaje significativo para nuestros alumnos es la experimentación, que, como dice Pozo Municio (1999):

Recordemos que la experiencia del aprendizaje debe tener un cierto grado de dificultad, algún grado de novedad, pero una globalidad adecuada (ni un desafío muy sencillo, ni uno muy complejo) para poder motivar al alumno, pues este grado de dificultad, acorde a sus conocimientos previos, es el que produce el conflicto cognitivo que convoca a una acción. Si el desafío no existe, porque todo es conocido por el alumno, no hay aprendizaje pues no hay movimiento de las estructuras cognitivas en el sujeto; pero si el desafío es muy 
ambicioso, si todo o casi todo es novedad, no hay problema ni conflicto cognitivo, entonces el aprendiz no encuentra el punto de partida, se paraliza o acciona sin sentido.

Nuestras actuales generaciones han nacido en la era digital, por lo que buscamos desafiarlos, motivarlos y llevarlos a la experimentación desde áreas que para ellos sean de interés y familiares. Haber nacido en una era donde la influencia de la revolución tecnológica ha influenciado su actuar y como resuelven problemas o enfocan su trabajo, el aprendizaje y los juegos de nuevas formas ha significado que absorban rápidamente la información multimedia de imágenes y videos, igual o mejor que si fuera texto; que esperan respuestas instantáneas; que están comunicados permanentemente y que también crean sus propios contenidos. A estas generaciones se les ha denominado "Nativos digitales".

Nativos digitales

De acuerdo a lo investigado algunas de las características y descripciones del concepto de Nativos Digitales que comentan García, Portillo, Romo y Benito son las siguientes: “La expresión nativos digitales ("digital natives”) fue acuñada por Marc Prensky en un ensayo titulado "La muerte del mando y del control", donde los identificaba con aquellas personas que han crecido con la Red y los distinguía de los inmigrantes digitales ("digital inmigrants"), llegando más tarde a las TIC.

Nacieron en la era digital y son usuarios permanentes de las tecnologías con una habilidad consumada. Su característica principal es sin duda su tecnofilia. Sienten atracción por todo lo relacionado con las nuevas tecnologías. Con las TICs satisfacen sus necesidades de entretenimiento, diversión, comunicación, información y, tal vez, también de formación. Estos nuevos usuarios enfocan su trabajo, el aprendizaje y los juegos de nuevas formas: absorben rápidamente la información multimedia de imágenes y videos, igual o mejor que si fuera texto; consumen datos simultáneamente de múltiples fuentes; esperan respuestas instantáneas; permanecen comunicados permanentemente y crean también sus propios contenidos. Forman parte de una generación que ha crecido inmersa en las Nuevas Tecnologías, desarrollándose entre equipos informáticos, videoconsolas y todo tipo de artilugios digitales, convirtiéndose los teléfonos móviles, los videojuegos, Internet, el email y la mensajería instantánea en parte integral de sus vidas y en su realidad tecnológica. Navegan con fluidez; tienen habilidad en el uso del ratón; utilizan reproductores de audio y video digitales a diario; toman fotos digitales que manipulan y envían; y usan, además, sus ordenadores para crear videos, presentaciones multimedia, música, blogs, etc.

A los nativos digitales les encanta hacer varias cosas al mismo tiempo: son multitarea. Afrontan distintos canales de comunicación simultáneos, prefiriendo los formatos gráficos a los textuales. Utilizan el acceso hipertextual en vez del lineal. Funcionan mejor trabajando en red. Y prefieren los juegos al trabajo serio.

Destacan la inmediatez en sus acciones y en la toma de decisiones. Acercándonos al área de la psicología, el nativo digital en su niñez ha construido sus conceptos de espacio, tiempo, número, causalidad, identidad, memoria y mente a partir, precisamente, de los objetos digitales que le rodean, pertenecientes a un entorno altamente tecnificado.

Se sostiene que el crecimiento en este entorno tecnológico puede haber influido en la evolución del cerebro de aquellos individuos. En concreto, se investiga el efecto de los juegos electrónicos en algunas habilidades 
cognitivas y la generación incluso una nueva estructura neuronal en los individuos.

Sin duda, su actividad con la tecnología configura sus nociones sobre lo que es la comunicación, el conocimiento, el estudio/aprendizaje e, incluso, sus valores personales.

Y, en resumen, podría afirmarse que los nativos digitales, lejos de ser una moda temporal, parecen ser un fenómeno que abarca el conjunto de una generación y que crece firmemente. En su capacidad multitarea, buscan pasar el menor tiempo posible en una labor determinada y abrir el mayor número de frentes posibles, provocando pérdidas de productividad, descensos en la capacidad de concentración y períodos de atención muy cortos con una tendencia a cambiar rápidamente de un tema a otro (en lugar de prestar atención de forma continua en un único objeto).

Aparece una forma de tratamiento de la información mucho más somera y superficial acompañada, en ocasiones, de una ansiedad relacionada con la obsesión de abrir el máximo número de comunicaciones o trabajos.

Respecto al ámbito exclusivamente educativo estos alumnos están mucho más predispuestos a utilizar las tecnologías en actividades de estudio y aprendizaje que lo que los centros y procesos educativos les pueden ofrecer. Esta situación puede llegar a generar un sentimiento de insatisfacción respecto a las prácticas escolares, creando una distancia cada vez mayor entre alumnos y profesores en relación a la experiencia educativa.

"Nativos digitales" es el término que describe a los estudiantes, menores de 30 años, que han crecido con la tecnología y, por lo tanto, tienen una habilidad innata en el lenguaje y en el entorno digital. Las herramientas tecnológicas ocupan un lugar central en sus vidas y dependen de ellas para todo tipo de cuestiones cotidianas como estudiar, relacionarse, comprar, informarse o divertirse.

Comparten con ellos los llamados "Inmigrantes digitales", que son aquellos que se han adaptado a la tecnología y hablan su idioma pero con "un cierto acento". Estos inmigrantes son fruto de un proceso de migración digital que supone un acercamiento hacia un entorno altamente tecnificado, creado por las TIC. Se trata de personas entre 35 y 55 años que no son nativos digitales y han tenido que adaptarse a una sociedad cada vez más tecnificada. Entre ambas generaciones las diferencias pueden ser importantes: En contraste con los inmigrantes, con cierta tendencia a guardar en secreto la información (el conocimiento es poder), los nativos digitales comparten y distribuyen información con toda naturalidad, debido a su creencia de que la información es algo que debe ser compartido.

Para los inmigrantes digitales, la capacidad de abordar procesos paralelos de los nativos digitales no son más que comportamientos con apariencia caótica y aleatoria.

A su vez, los procesos de actuación de los inmigrantes suelen ser reflexivos y, por lo tanto, más lentos, mientras que los nativos digitales son capaces de tomar decisiones de una forma rápida, sin pensarlo mucho, y en ambientes complejos.

Y en relación a los juegos electrónicos, los utilizados por los inmigrantes digitales en dé- cadas anteriores eran lineales, en funcionamiento y objetivos, mientras que los más recientes son más complejos, implicando la 
participación y coordinación de más jugadores. Además, los nativos digitales crean sus propios recursos: herramientas, armas, espacios, universos, etc., apropiándose de la tecnología, además de utilizarla.

\section{Enseñanza}

En el ámbito educativo la incorporación de los nativos digitales ha supuesto la introducción de una serie de desafíos.

Los nativos digitales, estudiantes de hoy en día y del mañana, no son los sujetos para los que los sistemas educativos y sus procesos de aprendizaje fueron diseñados. Sus profesores son, en el mejor de los casos, inmigrantes digitales que han hecho el esfuerzo de acercase a las nuevas tecnologías e intentan enseñar en un lenguaje muchas veces incomprensible para estos nativos digitales, pudiendo producirse cierto rechazo, o pérdida de atención o de interés.

Como indica Moreira, en su artículo sobre aprendizaje significativo, enfocándose en la teoría de Ausubel, "Aprendizaje significativo" es el proceso a través del cual una nueva información (un nuevo conocimiento) se relaciona de manera no arbitraria y sustantiva (no-literal) con la estructura cognitiva de la persona que aprende. En el curso del aprendizaje significativo, el significado lógico del material de aprendizaje se transforma en significado psicológico para el sujeto. Para Ausubel (1963), el aprendizaje significativo es el mecanismo humano, por excelencia, para adquirir y almacenar la inmensa cantidad de ideas e informaciones representadas en cualquier campo de conocimiento. No-arbitrariedad y sustantividad son las características básicas del aprendizaje significativo. No-arbitrariedad quiere decir que el material potencialmente significativo se relaciona de manera no-arbitraria con el conocimiento ya existente en la estructura cognitiva del aprendiz. O sea, la relación no es con cualquier aspecto de la estructura cognitiva sino con conocimientos específicamente relevantes a los que Ausubel llama subsumidores. El conocimiento previo sirve de matriz "ideacional" y organizativa para la incorporación, comprensión y fijación de nuevos conocimientos cuando éstos "se anclan" en conocimientos específicamente relevantes (subsumidores) preexistentes en la estructura cognitiva. Nuevas ideas, conceptos, proposiciones, pueden aprenderse significativamente (y retenerse) en la medida en que otras ideas, conceptos, proposiciones, específicamente relevantes e inclusivos estén adecuadamente claros y disponibles en la estructura cognitiva del sujeto y funcionen como puntos de "anclaje" a los primeros. Sustantividad significa que lo que se incorpora a la estructura cognitiva es la sustancia del nuevo conocimiento, de las nuevas ideas, no las palabras precisas usadas para expresarlas. El mismo concepto o la misma proposición pueden expresarse de diferentes maneras a través de distintos signos o grupos de signos, equivalentes en términos de significados. Así, un aprendizaje significativo no puede depender del uso exclusivo de determinados signos en particular. La esencia del proceso de aprendizaje significativo está, por lo tanto, en la relación no arbitraria y sustantiva de ideas simbólicamente expresadas con algún aspecto relevante de la estructura de conocimiento del sujeto, esto es, con algún concepto o proposición que ya le es significativo y adecuado para interactuar con la nueva información. De esta interacción emergen, para el aprendiz, los significados de los materiales potencialmente significativos (o sea, suficientemente no arbitrarios y relacionables de manera no-arbitraria y sustantiva a su estructura cognitiva). En esta interacción es, también, en la que el conocimiento previo se modifica por la adquisición de nuevos significados. Queda, entonces, claro que en la perspectiva ausubeliana, el conocimiento previo (la estructura cognitiva del aprendiz) es la variable crucial para el aprendizaje significativo. Con la estructura cognitiva solamente de manera arbitraria y literal que no da como resultado la adquisición de significados para el sujeto, el aprendizaje se denomina mecánico o automático. La 
diferencia clave entre aprendizaje significativo y aprendizaje mecánico está en la capacidad de relación con la estructura cognitiva: no arbitraria y sustantiva versus arbitraria y literal. No se trata, pues, de una dicotomía, sino de un continuo en el cual éstas ocupan los extremos. El aprendizaje significativo más básico es el aprendizaje del significado de símbolos individuales (típicamente palabras) o aprendizaje de lo que ellas representan. Ausubel denomina aprendizaje representacional a este aprendizaje significativo.

\section{El aprendizaje experiencial}

El aprendizaje experiencial, de acuerdo a Romero Ariza (2010) está cobrando especial importancia en los últimos años, lo que puede entenderse teniendo en cuenta las actuales tendencias educativas y las demandas sociales. En un entorno rápidamente cambiante debido al nivel de progreso alcanzado, en el que cada día se amplían los límites del conocimiento en las distintas disciplinas a través de la investigación, y donde los nuevos avances se difunden fácilmente gracias a las actuales tecnologías de la información y la comunicación, es lógico que evolucionen las necesidades formativas y el perfil profesional exigido, necesarios para desenvolverse satisfactoriamente en estas circunstancias. Además, la posibilidad de acceso a numerosas bases de datos y fuentes de información a través de un simple clic de ratón, exige individuos capaces de gestionar adecuadamente estos recursos y utilizarlos de acuerdo a sus necesidades. Para ello, han de poseer las destrezas y criterios que les permitan discriminar la información relevante de la accesoria o prescindible, y más aún, la rigurosa, de aquella proveniente de fuentes poco fiables. De este análisis se desprende fácilmente que, la capacidad de análisis crítico y de aplicación del conocimiento ocupan un lugar predominante sobre la mera adquisición de conceptos teóricos. Por ello, se hace más necesario que nunca revisar las pedagogías y metodologías didácticas empleadas, de modo que no estén enfocadas a la transmisión de información, sino a la promoción de competencias en los individuos. Una de las competencias más ampliamente demandada en el contexto actual, es la relacionada con la habilidad de aprender de forma autónoma. Esta competencia garantiza que el sujeto sea capaz de responder a una sociedad rápidamente cambiante, a través de un aprendizaje continuado a lo largo de toda su vida. La capacidad de aprender a aprender exige la habilidad para aprovechar todos nuestros sentidos (vista, oído, olfato, tacto, gusto) y nuestra interacción con el medio, para construir conocimiento. Esta habilidad se maximiza si sabemos emplear el potencial de todos los estímulos físicos que recibimos, junto con nuestra inteligencia matemática y lingüística, para aprender. Desde esa perspectiva, muchos autores defienden el valor del aprendizaje experiencial para promover la capacidad de aprender a aprender (Department for Education and Skills, UK, 2006). Más aún, el aprendizaje experiencial ofrece una oportunidad única para conectar la teoría y la práctica. Cuando el alumnado se enfrenta al desafío de responder a un amplio abanico de situaciones reales, se consolida en él un conocimiento significativo, contextualizado, trasferible y funcional y se fomenta su capacidad de aplicar lo aprendido. Los aspectos brevemente comentados, junto con el creciente interés por buscar nuevas formas de enseñar y de aprender, que promueven el desarrollo de competencias, justifican la especial atención que se está prestando a la integración de experiencias de aprendizaje fuera del aula, como mecanismos para complementar o potenciar la enseñanza formal. De ahí que exista un movimiento importante, destinado a investigar las posibilidades formativas en los lugares de trabajo, o que se promuevan iniciativas tales como la que inspira la elaboración y publicación del Manifiesto por el Aprendizaje Fuera del Aula (Department for Education and Skills, UK, 2006). Estas tendencias quedan también reflejada en algunos de los comunicados publicados por la Comisión Europea, que ponen de manifiesto el interés por el aprendizaje basado en la experiencia en contextos informales o no formales, incluyendo el aprendizaje en el lugar de trabajo. 
Smith (2001)señala que uno de los rasgos característicos del aprendizaje experiencial es que involucra al individuo en una interacción directa con aquello que se está estudiando, en lugar de una mera "contemplación" o descripción intelectual. No obstante, este autor enfatiza que no basta la experiencia para asegurar el aprendizaje, sino que éste está íntimamente ligado a un proceso de reflexión personal, en el que se construye significado a partir de la experiencia vivida. Sin embargo, actualmente no existe un marco teórico consolidado o ampliamente aceptado para explicar el aprendizaje experiencial. Uno de los argumentos esgrimidos para justificar la pertinencia de su trabajo es el hecho de que, puesto que los individuos aprenden continuamente fuera de los contextos formales, como consecuencia de su experiencia e interacción con el medio, el estudio de otros tipos de aprendizaje que se desarrollan espontáneamente en ambientes distintos a las aulas, podría permitir entender y aprovechar su potencial formativo. En su intento por establecer un marco conceptual, Chisholm y otros(2009) revisan distintas teorías previas sobre aprendizaje experiencial, utilizando como punto de partida el modelo propuesto por Dewey (1938; citado en Chisholm y otros, 2009) y retomado posteriormente por Itin, 1999. Dewey reivindica el potencial de la experiencia para promover conocimiento, entendiendo que los individuos aprenden, cuando encuentran significado en su interacción con el medio. El modelo sobre aprendizaje experiencial de este autor distingue distintas fases: experiencia concreta, reflexión, conceptualización abstracta y aplicación. Por lo tanto, de acuerdo a esa perspectiva, el aprendizaje se inicia a partir de una experiencia concreta, la cual es interpretada por el individuo a través de la reflexión y la conceptualización. La última fase contemplada en el modelo de Dewey es la de aplicación, que supone la capacidad de transferir el nuevo conocimiento a otras situaciones. Además, el marco teórico comentado, enfatiza el papel clave que el conocimiento previo y las experiencias vividas anteriormente por el sujeto, tienen sobre todo el proceso. En el modelo de aprendizaje experiencial de Dewey, la construcción de conocimiento a partir de una experiencia concreta se representa como un proceso cíclico, en el que las distintas fases (experiencia concreta, reflexión, conceptualización y aplicación) están interrelacionadas. Esta representación indica también que, el proceso de aprendizaje requiere de la integración de cada una de las fases. De este modo, no basta con una experiencia para provocar conocimiento, sino que para que esto ocurra realmente, es necesario la participación e implicación cognitiva del sujeto, buscando sentido a lo experimentado, relacionándolo con su conocimiento previo y desarrollando estructuras conceptuales que le permitan aplicar el nuevo conocimiento a diversas situaciones. Itin (1999) propuso lo que se ha denominado el modelo del diamante, en el que además de integrar las fases del aprendizaje experiencial propuestas por Dewey, muestra un entramado de interrelaciones multidireccionales "entorno-educador-aprendiz", enfatizando el papel clave del profesor como orientador y dinamizador del proceso. El educador por tanto, ha de seleccionar un contexto que aporte una experiencia rica en estímulos de aprendizaje y ha de incentivar la curiosidad y el interés del aprendiz, favoreciendo su capacidad de reflexión, de conceptualización y de aplicación de conocimiento. El marco teórico de Itin (1999) describe el aprendizaje experiencial como un proceso formativo en el que se consigue implicar al individuo físicamente, socialmente, intelectualmente, cognitivamente y emocionalmente a través de una experiencia concreta, que le ofrece un reto, no exento de un nivel mesurado de riesgo y posibilidad de fracaso. En este proceso, el aprendiz es animado a formular problemas e hipótesis, a experimentar y a aplicar su creatividad e ingenio para buscar respuestas y soluciones, desarrollando conocimiento. El aprendizaje experiencial implica una intensa actividad cognitiva por parte del sujeto, que se esfuerza por encontrar sentido e interpretar el mundo, por lo que, según este autor, conlleva un aprendizaje de segundo o tercer orden. El aprendizaje de tercer orden es un aprendizaje reflexivo que va más allá; hasta el punto de, como consecuencia de la interpretación profunda de la experiencia vivida, cuestionar hipótesis ampliamente aceptadas y revisar o modificar ideas fuertemente arraigadas. Se trata por tanto, de lo que las corrientes constructivistas asocian a los procesos de cambio conceptual o modificación de 
las estructuras cognitivas del sujeto. De esa forma, se defiende el potencial de la interacción con la realidad para desarrollar nuevo conocimiento. Desde su punto de vista, la formulación de problemas en contextos complejos y multidisciplinares y la necesidad de buscar respuestas o soluciones a dichos problemas, involucran al sujeto en procesos cognitivos, que conllevan un aprendizaje mucho más profundo y rico que aquel, que tradicionalmente se ha llevado a cabo en las aulas. Otro de los modelos teóricos que pueden resultar relevantes para caracterizar el aprendizaje experiencial es el de Epstein (1994), que defiende que existen dos modos interactivos para procesar los hechos y fenómenos que nos rodean: uno racional y otro emocional. Lo que se ha denominado en ocasiones el subconsciente guía el comportamiento del sujeto de forma intuitiva y le permite frecuentemente, responder a situaciones de forma más eficaz, que la que hubiese resultado de un procesamiento racional. Por ello, Epstein declara que ignorar la participación del cerebro emocional en el procesamiento de nuestra experiencia, supone obviar uno de los mecanismos naturales operantes en el ser humano, mientras que tomar conciencia de su existencia puede ayudarnos a adquirir un mejor conocimiento, control y aprovechamiento de nuestras potencialidades. Este modelo está en consonancia con las corrientes que defienden el papel de la inteligencia emocional y la importancia de dotar a los individuos de estrategias para desarrollarla. En este sentido, Chisholm y otros (2009)defienden que el trabajo de Epstein aporta un marco teórico adecuado para describir el aprendizaje que tiene lugar en contextos reales. No obstante, asumiendo que en el aprendizaje espontáneo y cotidiano frecuentemente predomina el componente subconsciente o emocional sobre el racional, estos autores resaltan la importancia de potenciar la reflexión, como instrumento eficaz para tomar consciencia del procesamiento intuitivo o experiencial de la información. De esta forma, el individuo sería capaz de analizar el conocimiento tácito presente en las situaciones reales, e integrarlo con el conocimiento explícito y racional. Sobre la necesidad de establecer un modelo ampliamente aceptado para caracterizar el aprendizaje experiencial se cree que ayudaría a superar las reticencias de algunos profesores y académicos conservadores, ante la utilización del aprendizaje fuera del aula o el aprendizaje en el lugar de trabajo, como formas valiosas para complementar o potenciar la formación en el aula. Estas aproximaciones podrían además, aportar nuevas fórmulas educativas, que respondan mejor a las actuales demandas formativas: desarrollo de competencias y promoción de aprendices autónomos y reflexivos. Con este propósito, sería útil encontrar los rasgos comunes presentes en cada una de las teorías sobre aprendizaje experiencial, revisadas anteriormente. No obstante, también existe consenso en torno a la idea de que, no basta la experiencia para provocar aprendizaje. Por ello, las distintas aproximaciones teóricas al aprendizaje experiencial, acaban de algún modo, señalando el papel clave de la inteligencia racional o de la reflexión, para interpretar y aprovechar los estímulos y la información proveniente del medio. La reflexión se señala por tanto, como la clave para garantizar la construcción de conocimiento a partir de la experiencia.

En los últimos años, se ha avanzado considerablemente en la comprensión acerca de cómo el cerebro trabaja y se asume la existencia de distintos estilos de aprendizaje. Teniendo en cuenta estos conocimientos, los resultados de diversas investigaciones sugieren que sería muy interesante despertar y potenciar en los sujetos, la capacidad de aprovechar su experiencia y su interacción con el medio para aprender. Aunque el aprendizaje experiencial puede ser considerado como la forma más primitiva y auténtica de aprendizaje, en la actualidad, existe un interés creciente por estudiar sus peculiaridades, de modo que pueda ser utilizado de forma consciente y programada, como vehículo formativo, tal y como se viene manifestando a lo largo del presente trabajo. Dillon y otros en 2006 publicaron un trabajo de revisión, recogiendo algunas evidencias aportadas por la investigación educativa, sobre el valor del aprendizaje fuera del aula. Otros autores defienden que el aprendizaje fuera del aula puede ser más efectivo que el tradicional para promover el desarrollo de habilidades cognitivas (Eaton, 
2000), mientras que otros, en relación con la posibilidad de potenciar el rendimiento académico a través del aprendizaje experiencial, ponen el énfasis en la conveniencia de conectar las salidas didácticas, con los contenidos trabajados en el aula (Uzzell y otros 1995). Sin embargo, se ha enfatizado el hecho de que, no basta una experiencia o una salida fuera del aula para garantizar la construcción de conocimiento. Entonces, ¿qué características de una salida fuera del aula hacen que sea efectiva para promover aprendizaje? Uno de los aspectos claves relacionados con el aprendizaje experiencial, es el lugar elegido para llevarlo a cabo, ya que éste supone uno de los valores añadidos respecto a la enseñanza formal en la escuela (Dillon y otros, 2006). La enseñanza formal está sujeta a una serie de limitaciones, impuestas, entre otras causas, por el espacio en el que se desarrolla, es decir, el aula. En cambio, tal y como indica su nombre, el aprendizaje experiencial se inicia a partir de una experiencia rica en estímulos, que promueve en el sujeto la necesidad de buscar sentido y explicación a lo percibido. Por lo tanto, las salidas didácticas se caracterizan no sólo por estimular el interés y la curiosidad del individuo por aprender, involucrándolo en su propio proceso de aprendizaje, sino también por favorecer la construcción de un conocimiento contextualizado y especialmente significativo, fruto de la interpretación de aquello que percibimos. La elección del lugar ha de venir determinada en parte, por los objetivos formativos perseguidos. Además, es interesante que una vez que se haya seleccionado el entorno en el que se va a llevar a cabo la salida didáctica, se estudie bien para evitar imprevistos o factores adversos, y para asegurar que se aprovecha al máximo sus peculiaridades y potencial para promover aprendizaje. Obviamente, otro de los aspectos a tener en cuenta para garantizar el éxito de las visitas fuera del aula es a quién van dirigidas, de modo que podamos adaptarlas al nivel de desarrollo y de madurez de los destinatarios, así como a sus intereses y motivaciones. Para ello, es importante conocer las capacidades y el conocimiento previo del alumnado, para facilitar que los estudiantes puedan construir significado a partir de sus estructuras cognitivas. De igual manera, puede resultar de gran utilidad indagar sobre cuáles son sus necesidades afectivas y sociales y sus principales fuentes de interés y motivación. Existen importantes evidencias sobre la influencia que en los resultados finales alcanzados, tiene la preparación de la salida fuera del aula. Por ejemplo, Ballantyne y Packer (2002), encontraron diferencias significativas entre los estudiantes que habían realizado preactividades antes de la visita didáctica, con respecto a aquellos que no las habían hecho. Los alumnos que habían participado en actividades previas a las excursiones mostraron mayor predisposición y motivación hacia lo que iban a encontrar y aprovecharon mejor la salida. Los debates, las discusiones y las explicaciones previas, también se han mostrado como actividades que tienen una influencia positiva sobre la probabilidad de promover aprendizaje, a partir de la experiencia fuera del aula (Healey y otros, 2001). Estos autores además, Ilaman la atención sobre la pertinencia de asegurar que todos los estudiantes puedan beneficiarse de estas salidas, generando materiales para facilitar la adaptación del alumnado con necesidades especiales. Otro aspecto a tener en cuenta en la utilización del aprendizaje experiencial como complemento a la enseñanza formal, es la conveniencia de encontrar un equilibrio adecuado en el grado de estructuración de las actividades, de manera que no se propongan tareas ni demasiado abiertas, ni excesivamente rígidas. Más aún, se debe ofrecer variedad en el tipo de actividades a realizar, de modo que sea posible adaptarnos a los distintos estilos de aprendizaje existentes en el grupo clase. En esta línea, algunos autores señalan la dificultad de conciliar, en el diseño y planificación de la salida, la evitación de riesgos, con la intención de ofrecer un cierto nivel de iniciativa y desafío a los estudiantes (Openshaw y Whittle, 1993). Hay investigaciones que señalan que las hojas de trabajo para el alumnado o la obligación de realizar posteriormente un informe sobre la excursión, no son medidas muy populares entre los discentes y frecuentemente, no aportan excesivos beneficios cognitivos. Por ello, es importante encontrar formas motivadoras de ayudarles a sacar el máximo partido formativo a la excursión, estimulando su curiosidad, sus ganas de aprender, de experimentar e investigar, y de llegar más allá, por sí 
mismos (Ballantyne y Packer, 2002). En este sentido, el papel del profesor para motivar y dirigir el interés es también un factor clave (Emmons, 1997). Algunos artículos científicos ofrecen recomendaciones concretas, en las que se tienen en cuenta algunos de los aspectos comentados anteriormente, con el propósito de establecer cómo preparar adecuadamente una salida y potenciar al máximo sus efectos cognitivos y afectivos (Orion y Hofstein, 1994). Orion y Hofstein enfatizan también, la importancia de hacer una buena evaluación y seguimiento del impacto que estas experiencias, tienen sobre el aprendizaje de los estudiantes. Llegados a este punto, sería conveniente mencionar algunos factores que se oponen, de alguna manera, a la mayor utilización del aprendizaje experiencial en la escuela. Uno de esos factores es la falta de confianza del docente, sobre su capacidad para responder a los retos asociados a una salida. Esto se puede deber en parte, a su preocupación por no dominar suficientemente los contenidos que se van a trabajar con la salida didáctica, o aquellos que pudieran surgir sobre la marcha, o a su inseguridad respecto a los conocimientos requeridos para llevar a cabo este tipo de iniciativas, de forma eficaz. Otras veces, el rechazo de los profesores y profesoras a las salidas didácticas, se debe a la necesidad de asumir un cierto nivel de riesgo, afrontando la responsabilidad de garantizar la seguridad del alumnado, durante la excursión. También se alega a la falta de recursos o de apoyo institucional, para argumentar el escaso uso del aprendizaje experiencial por parte de los docentes. Otra de las razones esgrimidas para justificar la reticencia de algunos docentes frente a la integración del aprendizaje experiencial, tiene que ver con las exigencias del currículo y la escasez de tiempo disponible para hacer frente a dicho currículo. Estos aspectos se podrían afrontar promoviendo un cambio de mentalidad respecto a los objetivos educativos perseguidos, y sobre todo, respecto a las formas de evaluación implementadas.

Frecuentemente, el profesor se ve presionado por la necesidad de preparar a sus estudiantes para la superación de exámenes, centrados en la memorización de conceptos o en la resolución de actividades tipo, coherentes con el enfoque predominante en el currículo rígido vigente. La búsqueda de aprendizajes profundos, significativos y duraderos en el tiempo, que garanticen la capacidad del individuo para transferir el conocimiento a nuevas situaciones y resolver problemas, exige no sólo la implementación de nuevas pedagogías, sino también, de nuevas formas de evaluar.

\section{El mensaje audiovisual}

Como indica Morales en su publicación "La fusión audiovisual y su relación con la captación de la atención de los mensajes", la estructura del mensaje audiovisual se define a partir de la sucesión organizada de imágenes y sonidos que reproducen perceptivamente unos contenidos dirigidos a la transmisión de información dotada de carga significativa. Sin embargo, los conceptos e instrumentos básicos que la definen y modelan no siempre se orientan hacia este propósito y son incapaces de captar la atención o mejorar la comprensión del mensaje en los sujetos destinatarios. El artículo reflexiona acerca de la pertinencia de algunos conceptos del lenguaje audiovisual y formula una nueva propuesta dirigida a canalizar el potencial comunicativo del mensaje a partir de la fusión perceptiva de la imagen y el sonido en la consecución de estos objetivos.

El fortalecimiento de las estructuras empresariales dedicadas a la industria audiovisual no es meramente casual sino que ha impulsado la formación de holdings y alianzas estratégicas para aumentar la competitividad y alcanzar el liderazgo internacional del sector. Este hecho ha representado para los productores un giro en la dinámica empresarial en dos aspectos. Primero, ha supuesto un importante ahorro en los gastos de inversiónrenovación tecnológica. Esto pasa por afectar en el precio final de los servicios con relación a los costes habituales sugeridos por las grandes casas realizadoras o por los profesionales independientes acostumbrados a trabajar con tecnologías broadcast. En segundo lugar, ha producido una readaptación de las estructuras de 
trabajo marcada por unos niveles de precio relacionados con los gastos y nuevos costes del equipamiento empleado. De este modo, el aumento de la oferta ha provocado una disminución en el coste de los servicios, un aumento sustancial de la competitividad y una necesaria fusión de roles profesionales para adecuarlos a una lógica que ahora necesita.

Influencia de la convergencia en las dinámicas de comunicación

Desde la esfera del usuario, principalmente, el cambio tecnológico ha permitido el acceso al nuevo universo de la interactividad. Podemos escuchar el sonido o ver los subtítulos de un programa en diferentes idiomas y en tiempo real, suspender y retomar la reproducción, activar opciones de cambio de ángulo como un DVD interactivo, acceder a servicios exclusivos Pay Per View, estaciones de radio en calidad digital, entre otras prestaciones que resultan impensables en el contexto de la televisión analógica. A la par, se ha producido un incremento en el volumen de la oferta programática, debido a la diversificación e internacionalización de las empresas productoras en alianza estratégica con los operadores de cable y de televisión satelital. Actualmente, el campo de actuación de los contenidos no se adscribe únicamente a la televisión sino que los mismos productores rediseñan sus mensajes y los adaptan a nuevos formatos y para ser exhibidos por diferentes medios. Rompiendo definitivamente con el modelo de comunicación unidireccional tradicional, ahora el usuario selecciona el producto, lo consume en consonancia con sus espacios disponibles y si corresponde, envía un retorno o valoración de su experiencia a un centro de operaciones que procesa automáticamente la información y la reutiliza para reconducir los tratamientos o la forma estilística del mensaje, contribuyendo así a las bases de lo que podríamos denominar un proceso de comunicación con retorno inmediato

El efecto en los perfiles y la forma de los discursos

Solo dos décadas atrás, el reconocimiento profesional del realizador o montador pasaba por su buen criterio o control de las formas y estructuras audiovisuales, muy por encima del control de un equipo más simple y con capacidades limitadas. Ahora, con la digitalización, el perfil profesional del audiovisual da un vuelco y hace imponer un mayor dominio tecnológico, muchas veces por sobre las capacidades creativas y estéticas, porque la herramienta está asociada directamente con el logro de los objetivos comunicativos adscritos al mensaje. Este hecho, unido a la creciente oferta de aplicaciones informáticas de montaje de sonido y vídeo de uso libre o de bajo coste disponibles, facilita la utilización masiva de nuevo software y terminan por dar preferencia muchas veces a la operatividad, por encima del dominio de los aportes conceptuales y narratológicos.

Todas estas condiciones marcadas por el cambio tecnológico han resultado útiles y propicias para que los realizadores experimenten con nuevos estilos y tratamientos en su afán por romper permanentemente con unas estructuras, la lógica narrativa convencional y proyectar una creatividad innovadora a partir de la imagen y el sonido. La animación multimedia y el uso de recursos y tratamientos gráficos digitales permiten fácilmente transformar las estructuras espaciales de la imagen en el tiempo, creando personajes y formas irreales con elevada verosimilitud. Los acercamientos y alejamientos generados por la imagen 3D, sin pérdida de resolución, rompen por completo con la visión clásica de la construcción de los discursos. La imagen del mismo personaje se corta creando saltos de imagen intencionales con el fin de mantener el hilo narrativo sin respetar el cambio de posición de los elementos al interior del encuadre, eliminando por completo el tradicional valor semántico del cambio de plano que hace pocas décadas todos los cineastas intentaban defender. Todo esto nos lleva a 
efectuar una revisión de los conceptos fundamentales para ver si continúan respondiendo eficazmente a estas dinámicas de comunicación.

Mensaje audiovisual y complejidad de la información

Desde hace varias décadas diversos autores han formulado modelos donde los mensajes se abordan como conjuntos dotados de un volumen de información variable. Noel Burch, por ejemplo, habla de "repertorio de sistemas simples" y "dialécticas complejas" (Burch, 1998, p. 59). Giles Deleuze divide en "nivel del cuadro y nivel del plano movimiento" dos estructuras autónomas de construcción y de interacción con los mensajes (Deleuze, 1984, p. 27). Desde el campo de la psicología, Annie Lang define la complejidad del mensaje a partir de las demandas temporales de procesamiento para ejecutar de manera eficiente tres subprocesos consecutivos: codificación, almacenamiento y recuperación de la información (Lang, 1995). Los estudios empíricos que respaldan esta teoría sugieren la existencia de un posible vínculo entre las estructuras y patrones físicos del mensaje y su sentido significativo (Bolls \& otros, 2001; Reeves \& otros, 1999).En un contexto comunicativo específico esto puede representar, que si el emisor regula la activación significativa del mensaje podrá activar un nivel de atención en el receptor, necesario para seguir de forma correlacionada una cadena de localizaciones relevantes que le permitan descifrar el significado o sentido. La ejecución de este proceso constituye una fase previa a través de la cual el receptor logra decodificar y comprender un conjunto de rasgos relevantes del mensaje que lo conducen a descubrir su sentido. Este razonamiento es coherente con el planteamiento que defiende la adecuación de los discursos a las capacidades reales de percepción del individuo (Mitry, 2002, p. 474); entonces, sobre la base de una "coincidencia" entre emisor receptor, a través del mensaje, podrá decodificarse correctamente cualquier organización y, por tanto, extraerse de ella su significado exacto. No obstante, primeramente debemos encontrar el componente clave que nos conduzca al hallazgo de dicha coincidencia entre imagen y sonido.

\section{Coherencia semántica}

La debilidad operativa de los conceptos de Secuencia, Escena, Plano y la necesidad de construir un procedimiento que sea eficiente, independientemente del contenido particular del mensaje, nos lleva a reformular el concepto operativo y su naturaleza, a partir de un atributo que nos permita identificar y diferenciar claramente los rasgos visuales y sonoros de un segmento del mensaje en relación con otros conjuntos. Empleamos el concepto de Coherencia Semántica, entendida como una organización discursiva audiovisual relacionada ordenadamente y con sentido único y diferenciable. Así, tanto el flujo de la imagen como el del sonido configuran un Sistema Visual o Sonoro, respectivamente, delimitado a partir de su coherencia semántica y su relación/no relación con otros sistemas visuales y sonoros presentes en el conjunto de la narración audiovisual. Este concepto, permite unir en un solo conjunto los significados individuales que emanan del flujo visual y sonoro, de modo que la suma de ambos conlleve a un indicador coincidente que facilite su reconocimiento. Por tanto si aplicamos este concepto a la estructura del mensaje audiovisual tendremos que el Sistema Sonoro se define como:

Un sonido o conjunto de sonidos organizados según rasgos acústicamente reconocibles, diferenciables y objetivables a partir de atributos formales, relaciones internas y características perceptivas que se distribuyen en el tiempo y en el espacio, cuya organización sistemática integral posee una coherencia semántica de sentido único y diferencial a partir de su relación directa o indirecta con la imagen sincrónica correspondiente. 
Luego de analizar tres grandes áreas; nuestros alumnos, los nativos digitales; la importancia del aprendizaje significativo junto a la enseñanza experiencial y el mensaje audiovisual que se puede construir hoy, junto con los recursos que nos entrega la tecnología, cada vez más cercana y accesible, nos damos cuenta que las tres áreas se interconectan en el ejercicio del Diseño Audiovisual Experimental. Al pertenecer nuestros alumnos a la generación de nativos digitales, pensamos que debemos acercarnos a ellos desde su perspectiva de vida, desde sus herramientas y habilidades si queremos lograr una motivación real en su trabajo, en como abordan el diseño y el trabajo en general, buscando nuevas herramientas que puedan conectar al docente con el alumnado de manera significativa y bien preparada para que el aprendizaje a través de la experiencia y experimentación llegue al nivel de reflexión del alumno y así poder entender la disciplina del Diseño Gráfico en todas sus dimensiones, y utilizar el medio Audiovisual como un recurso didáctico dentro de sus posibilidades de practicar el Diseño Gráfico, sin embargo, creemos que es una de las disciplinas asociadas al diseño que se acerca más a los intereses actuales de nuestros alumnos, lo que nos lleva a pensar que unir la experimentación con temas de su interés, como es lo audiovisual y los elementos que involucra su realización, nos asegura un aprendizaje significativo por parte de los estudiantes.

\section{Bibliografía}

Ballantyne, R., Packer, J. (2002). Nature based excursions: school studentes percepctions of learning in natural environments, en International research in geographical and environmental education.

Bolls \& otros. (2001). The effects of message valence and listener arousal on attention, memory, and facial muscular responses to radio advertisements.

Burch, N. (1998). Praxis del cine Fundamentos. Colección arte, serie cine. Madrid.

Chisholm, C. U. (2009). The characterization of work-based learning by consideration of the theories of experiential learning, en European Journal of Education.

Deleuze, G. (1984). Estudios sobre cine. Barcelona: Instituto de Investigaciones GFK.

Dillon, J., Rickinson, M., Teamey, K., Morris, M., Young Choi, M., Benefield, P., Department for education and skills, Nottingham, UK. (2006). Learning outside the classroom manifesto.

Eaton, D. (2000). Congnitive and affective learning: evidence in outdoor education, en Dissertation abstracts International, Section A: Humanities and social sciences.

Epstein, S. (1994). Integration of the cognitive and the psychoanalytical unconscious.

Garcia, F.; Portillo, J.; Romo, J.; Benito, M. (2007). Nativos digitales y modelos de aprendizaje. Universidad de País Vasco / EuskalHerrikoUnibertsitatea (UPV/EHU). Desde: http:// spdece07.ehu.es/actas/Garcia.pdf

Itin, C. M. (1999). Reasserting the philosophy of experiential education as vehicle for change in the 21st. Century, en Journal of experiential education. 
Lang, A., (1995). The effects of emotional arousal and valence on television viewers, en Journal of broadcasting and electronic media.

Moreira, M. A. (2010). Aprendizaje significativo: Un concepto subyacente. Instituto de Física, UFRGS, Campus 91501-970. Porto Alegre, RS, Brasil. Desde: http://www.if.ufrgs. br/ moreira/apsigsubesp.pdf

Morales, L. F. (2009). La Fusión Audiovisual y su relación con la captación de la atención de los mensajes. Desde: http://www.razonypalabra.org.mx/N/n67/varia/lfmorales.html

Mitry, J., (2002). Estética y psicología del cine.

Openshaw, P. H.; Whittle, S. J. (1993). Ecological field teaching: How can it be made more effective?, en Journal of biological education.

Orion, N.; Hofstein, A. (1994). Factors that influence learning during a scientific field trip in a natural environment, en Journal of research in science teaching.

Pozo, J. I. (1999). Aprendices y Maestros: La nueva cultura del aprendizaje.

Reeves, B. \& otros (1999). The effects of screen sie and message content on attention and arousal.

Romero Ariza, M. (2010). El aprendizaje experiencial y las nuevas demandas formativas. Revista de Antropología experimental $n^{\circ}$ 10. Especial Educación 8: 89-102. Universidad de Jaen (España). Desde: http://revista.ujaen.es/huesped/rae/articulos2010/edu1008pdf.pdf

Smith, M. K. (2001). David A Kolb on experiential learning, The encyclopedia of informal education. Desde: http://infed.org/mobi/david-a-kolb-on-experiential-learning/

Uzzel, D. L.; Rutland, A.; Whistance, D. (1995). Questioning values in environmental education.

Abstract: This article proposes a reflection about experimental design focusing on the teaching-learning process.

Key words: experimental design - teaching - learning.

Resumo: Este artigo propõe uma reflexão sobre os diferentes aspectos que fazem ao design experimental pondo ênfase no processo de ensino- aprendizagem.

Palavras chave: design experimental - ensino - aprendizagem.

Reflexión acerca del ejercicio audiovisual como medio de expresión del diseño gráfico experimental fue publicado de la página 25 a página39 en Cuadernos del Centro de Estudios de Diseño y Comunicación № 66 